3. Navia JL, Atik FA, Marullo A, Starling RC, Garcia M, Vega PR, et al. Bench repair of donor aortic valve with minimal access orthotopic heart transplantation. Ann Thorac Surg. 2005;80:313-5.

4. Boodhwani M, de Kerchove L, Glineur D, Rubay J, Vanoverschelde JL, Van Dyck M, et al. Aortic valve repair with ascending aortic aneurysms: associated le- sions and adjunctive techniques. Eur J Cardiothorac Surg. 2011;40:424-8. Epub 2011 Jan 13.

5. David TE, Feindel CM, Armstrong S, Maganti M. Replacement of the ascending aorta with reduction of the diameter of the sinotubular junction to treat aortic insufficiency in patients with ascending aortic aneurysm. J Thorac Cardiovasc Surg. 2007;133:414-8.

\title{
Surgical cryoablation for ventricular tachyarrhythmia in patients undergoing surgical ventricular restoration: Lessons learned from radiofrequency ablation
}

\author{
Rao V. Parachuri, FRCS(Cth), ${ }^{\mathrm{a}}$ and Srilakshmi M. Adhyapak, DNB, ${ }^{\mathrm{b}}$ Bangalore, India
}

With the limited number of available donor hearts, therapeutic options are limited even for those patients who are eligible for transplantation. The clinical presentation of patients with post-myocardial infarction left ventricular aneurysms is usually heart failure, angina, or ventricular tachyarrhythmia. In patients with ventricular tachyarrhythmia, the role of adjuvant arrhythmia surgery during surgical ventricular restoration is unquestionable. In patients who do not present with arrhythmia, however, the role of preoperative electrophysiologic testing to demonstrate inducibility of such arrhythmia is not clear.

The concomitant surgical procedures for arrhythmia in the late 1970s and early 1980s included map-guided or unguided endocardectomy and encircling cryoablation of the border zone. These procedures targeted ablation of ventricular tachyarrhythmia caused by reentrant circuits that were presumed to exist in the border zone. ${ }^{1}$ In the 1990 s, computer modeling, animal studies, and human studies demonstrated that such circuits contain a narrow isthmus of viable tissue and slow conduction that forms a critical part of the ventricular tachyarrhythmia reentrant circuit and is bound by infarcted tissue or anatomic barriers, such as the mitral valve annulus. ${ }^{2,3}$ Radiofrequency ablation is targeted at

From the Division of Cardiovascular Surgery, University of Pennsylvania, Philadelphia, Pa.

Disclosures: Authors have nothing to disclose with regard to commercial support.

Received for publication Jan 10, 2012; revisions received Jan 30, 2012; accepted for publication March 12, 2012; available ahead of print April 9, 2012.

Address for reprints: Srilakshmi M. Adhyapak, DNB, c/o V. Rao Parachuri, FRCS(Cth), Narayana Hrudayalaya Institute of Medical Sciences; 258/A, Bommasandra Industrial Area, Anekal Taluk, Bangalore 560099, India (E-mail: srili2881967@yahoo.com).

J Thorac Cardiovasc Surg 2012;144:724-6

$0022-5223 / \$ 36.00$

Copyright (c) 2012 by The American Association for Thoracic Surgery

http://dx.doi.org/10.1016/j.jtcvs.2012.03.023

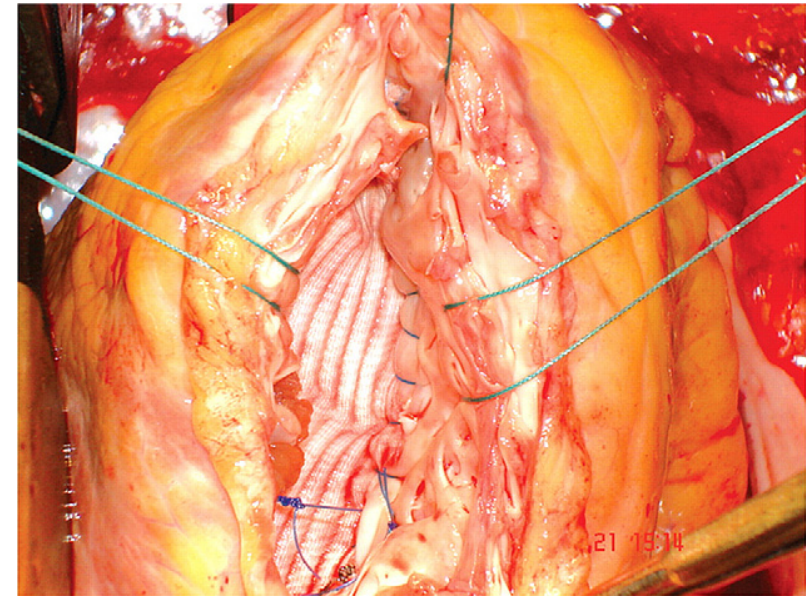

FIGURE 1. Linear endoventricular patch used to exclude the infarcted myocardium. (Reprinted with permission from Parachuri VR, Adhyapak SM, Kumar P, Setty R, Rathod R, Shetty DP. Ventricular restoration by linear endoventricular patchplasty and linear repair. Asian Cardiovasc Thorac Ann. 2008;16:401-6.)

ablating this isthmus to abolish the reentrant mechanism of ventricular tachyarrhythmia. This procedure is usually performed after mapping the isthmus by 3-dimensional cartography. Surgical mapping of the reentrant circuit is cumbersome, however, and we therefore modeled our cryoablation technique from available data on the anatomic location of the isthmus. We now evaluate the midterm results of surgical linear cryoablation of ventricular tachyarrhythmia in patients undergoing surgical ventricular restoration.

\section{CLINICAL SUMMARY}

We performed linear cryoablation in 6 patients presenting with spontaneous ventricular tachyarrhythmia who were 
TABLE 1. New York Heart Association functional class and echocardiographic left ventricular data

\begin{tabular}{|c|c|c|c|c|}
\hline & Preoperative & Postoperative (30 d) & 5-y Follow-up & $P$ value \\
\hline Left ventricular ejection fraction & $31.5 \% \pm 6.5 \%$ & $34.2 \% \pm 5.9 \%$ & $38.4 \% \pm 4.5 \%$ & $<.001$ \\
\hline Indexed end-diastolic volume (mL) & $140.3 \pm 38.3$ & $100.8 \pm 3.5$ & $68.4 \pm 12.4$ & $<.001$ \\
\hline Indexed end-systolic volume (mL) & $95.1 \pm 26.1$ & $66 \pm 21.7$ & $54.2 \pm 16.4$ & $<.001$ \\
\hline New York Heart Association functional class & III/IV & & $\mathrm{I} / \mathrm{II}$ & \\
\hline
\end{tabular}

Values are mean \pm SD. $P$ values were obtained by analysis of variance.

scheduled for surgical ventricular restoration. ${ }^{4}$ We have not conducted electrophysiologic testing for inducibility in patients who did not present with spontaneous ventricular tachyarrhythmia, and none of our patients underwent preoperative electrophysiologic testing for inducibility. Our technique of cryoablation is modeled after the principle of radiofrequency ablation of reentrant ventricular tachyarrhythmia. After opening the ventricular cavity parallel to the left anterior descending coronary artery in anterior ventricular aneurysms, we performed a linear cryoablation starting from the posterior mitral annulus and extending to the inferior aspect of the apical scar. We used a cryosurgical probe AA3 with a curved tip (Appasamy Associates, Chennai, India). The probe was applied at temperatures of $-60^{\circ} \mathrm{C}$ for 2 minutes at each point. Once this cryoablation was completed, a linear endoventricular patch was created to exclude the infarcted myocardium (Figure 1). The infarcted scar was not plicated, and the patch was sized visually.

Concomitant surgical procedures included coronary artery bypass grafting in 3 patients (with $2 \pm 1.2$ grafts) and mitral valve repair with a rigid Carpentier annuloplasty ring (Edwards [India] Pvt. Ltd, Mumbai, India) in 2 patients with mitral regurgitation of at least grade 2. All 6 patients were subjected to postoperative electrophysiologic testing for arrhythmia inducibility at 6 weeks to 6 months after the surgery. None had inducible arrhythmias. At 5-year follow-up, there were no deaths in this patient subgroup, with significant clinical improvements as assessed by New York Heart Association functional class and significant reverse remodeling as assessed by decreases in left ventricular end-systolic volumes and ejection fractions on 2-dimensional echocardiography (Table 1).

\section{DISCUSSION}

The mechanism for post-myocardial infarction ventricular tachyarrhythmia is reentry, which requires the presence of an isthmus. An isthmus is defined as conductive myocardial tissue delineated by nonconductive tissue. A depolarization wave front must cross this isthmus to perpetuate the tachyarrhythmia. As a consequence, ablation of the critical isthmus interrupts the tachyarrhythmia and prevents its reinducibility.

The localization of the critical isthmus in patients with a history of myocardial infarction was studied by de Chillou and coworkers. ${ }^{5}$ Four of 6 patients studied with anterior infarctions had anterior left ventricular aneurysms, and 5 of 12 patients studied with inferior infarctions had inferior left ventricular aneurysms. In $86 \%$ of patients, the reentrant circuits were anteroapical, inferolateral, and septal, anatomically perpendicular to the mitral annular plane. One of the factors responsible for the limited clinical success of ablation for ventricular tachyarrhythmia is that focal ablation may not prevent reestablishment of the reentrant circuit. Radiofrequency linear ablation is more appropriate in postinfarct ventricular tachyarrhythmia because it can transect the critical isthmus. The data of de Chillou and coworkers ${ }^{5}$ demonstrated a wide range $(6-36 \mathrm{~mm})$ of critical isthmus width values, which supports the need for linear ablation to eliminate the reentrant substrate of postinfarct ventricular tachyarrhythmia. We therefore based our procedure of linear cryoablation on these available data. A major limitation of our study is that the beneficial effects of revascularization, abolishment of mitral valve regurgitation, and concomitant cryoablation on the outcomes of heart failure and rhythm control could not be evaluated separately.

In conclusion, with a surgical linear cryoablation lesion similar to percutaneous radiofrequency ablation techniques, we had no deaths, found no inducible ventricular tachyarrhythmia, and saw no recurrences after 5 years in patients undergoing surgical ventricular restoration who presented with ventricular tachyarrhythmia.

\section{References}

1. Frapier JM, Hubaut JJ, Pasquié JL, Chaptal PA. Large encircling cryoablation without mapping for ventricular tachycardia after anterior myocardial infarction: long-term outcome. J Thorac Cardiovasc Surg. 1998;116: 578-83.

2. Bernstein R, Frame L. Ventricular reentry around a fixed barrier. Resetting with advancement in an in vitro model. Circulation. 1990;81:267-80.

3. Wilber DJ, Kopp DE, Glascock DN, Kinder CA, Kall JG. Catheter ablation of the mitral isthmus for ventricular tachycardia associated with inferior infarction. Circulation. 1995;92:3481-9. 
4. Parachuri VR, Adhyapak SM, Kumar P, Setty R, Rathod R, Shetty DP. Ventricular restoration by linear endoventricular patchplasty and linear repair. Asian Cardiovasc Thorac Ann. 2008;16:401-6.
5. de Chillou C, Lacroix D, Klug D, Magnin-Poull I, Marquié C, Messier M, et al. Isthmus characteristics of reentrant ventricular tachycardia after myocardial infarction. Circulation. 2002;105:726-31.

\title{
Cardiopulmonary bypass strategy with low-dose heparin and nafamostat mesilate in cardiac surgery: A safe option for patients with acute stroke
}

\author{
Naoto Morimoto, MD, PhD, Soichiro Henmi, MD, Masato Yoshida, MD, and Nobuhiko Mukohara, MD, \\ Himeji, Japan
}

Patients undergoing open cardiac surgical procedures with a history of acute stroke pose a difficult management problem. There is always the risk that cardiopulmonary bypass (CPB) and heparinization may induce intracranial hemorrhage. A multicenter study suggests that open cardiac surgical procedures can be performed safely 4 weeks after stroke $^{1}$; however, some patients with acute cardiogenic stroke occasionally require emergency surgery because of uncontrollable heart failure or ongoing thromboembolism.

Heparinized CPB with low systemic heparinization is among the therapeutic options when operating on patients with the risk of intracranial hemorrhage; however, low systemic heparinization could allow clot formation. ${ }^{2}$ Nafamostat mesilate (6-amino-2-naphthyl $p$-guanidinobenzoate dimethanesulfonate, currently available in Japan and Korea) is a serine protease inhibitor that has such activities as anticoagulant effect (by inhibiting coagulation factors, XIIa, Xa, and VIIa, along with thrombin), antifibrinolytic activities (by inhibiting tissue-type and urokinase plasminogen activators), and antiplatelet actions. ${ }^{3,4}$ Because of a short halflife of 8 minutes, it has recently been used mainly as an anticoagulant for hemodialysis ${ }^{5}$ and extracorporeal membrane oxygenation ${ }^{6}$ in patients with bleeding tendencies. Nafamostat mesilate has been widely used in Japan as an alternative anticoagulant agent during hemodialysis, and its in vivo effect as an anticoagulant has been established. ${ }^{3}$

In this study, we report a successful CPB strategy with low-dose heparin and nafamostat mesilate as an

\footnotetext{
From the Narayana Hrudayalaya Institute of Medical Sciences, ${ }^{\text {a }}$ Bangalore, India; and the Department of Cardiology, ${ }^{\mathrm{b}}$ St. John's Medical College Hospital, Bangalore, India. Disclosures: Authors have nothing to disclose with regard to commercial support.

Received for publication Dec 13, 2011; revisions received March 2, 2012; accepted for publication March 16, 2012; available ahead of print April 27, 2012.

Address for reprints: Naoto Morimoto, MD, PhD, Department of Cardiovascular Surgery, Himeji Cardiovascular Center, 520, Saishoko, Himeji, Hyogo, 670-0981, Japan (E-mail: naotofrcs@gmail.com).

J Thorac Cardiovasc Surg 2012;144:726-8

0022-5223/ $\$ 36.00$

Copyright (c) 2012 by The American Association for Thoracic Surgery http://dx.doi.org/10.1016/j.jtcvs.2012.03.030
}

anticoagulant to reduce the dosage of heparin for patients with acute stroke.

\section{MATERIALS AND METHODS}

With approval of the institutional review board and patient informed consent, patients who underwent cardiac surgery with CPB with low-dose heparin and nafamostat mesilate were included. From November 2007 and January 2010, we had 17 patients with courses complicated by acute stroke. The patient characteristics are listed in Table 1. Acute stroke was detected by diffusion-weighted magnetic resonance images in 16 cases, and 1 patient had subarachnoid hemorrhage from a ruptured mycotic aneurysm. Of these patients, 14 patients had a diagnosis of active infective endocarditis according to modified Duke criteria. The remaining 3 patients had acute pulmonary embolism with atrial septal defect, left ventricular thrombus, or left atrial myxoma. Mean age was $63.9 \pm 16.7$ years. Seven patients $(41.2 \%)$ were female. The indication for the operation was uncontrolled sepsis in 7 patients, uncontrollable heart failure in 5 patients, and ongoing thromboembolism in 5 patients. The mean interval from the onset of stroke to surgery was $2.9 \pm 0.4$ days. All operations were performed as routine procedures except for the CPB anticoagulation management. Brain computed tomography was performed within 3 days after the surgery in all cases.

\section{Anticoagulation Protocol During CPB}

Anticoagulation during CPB was managed as follows: before connection of the extracorporeal circuit, $0.8 \mathrm{mg} / \mathrm{kg}$ of nafamostat mesilate and $50 \mathrm{IU} / \mathrm{kg}$ of heparin (our normal dosage for CPB is $300 \mathrm{IU} / \mathrm{kg}$ ) were administered to obtain a diatomaceous earth (Celite; World Minerals Inc, Santa Barbara, Calif) activated clotting time (DEACT, measured with ACTII; Medtronic Blood Management, Parker, Colo) over 250 seconds. If DEACT did not rise above 250 seconds, a 200-IU dose of heparin was administered. CPB was composed of a roller pump (Mera HAS; Senko Medical Instrument Mfg Co Ltd, Tokyo, Japan), a silicon- and heparin-coated hollow-fiber polypropylene oxygenator (Mera NHP Excelung Prime HPO23WH-C; Senko) and a heparin-coated bypass circuit (Mera Exceline-S, 0.5-inch; Senko). After connection to the pump circuit, nafamostat mesilate and heparin were continuously infused through the venous line of the pump circuit at $0.8 / \mathrm{mg} /(\mathrm{kg} \cdot \mathrm{h})$ and $25 \mathrm{IU} /(\mathrm{kg} \cdot \mathrm{h})$, respectively. DEACT, for which blood samples were taken from the venous circuit line every 10 minutes, was maintained between 400 and 600 seconds during CPB. If DEACT exceeded 600 seconds, the continuous infusion of heparin was reduced. An additional bolus injection of $100 \mathrm{IU}$ of heparin was administrated when DEACT fell below 400 seconds. Furthermore, kaolin-measured ACT (KACT, measured with Hemochron401; International Technidyne Corp, Edison, $\mathrm{NJ})$ was monitored simultaneously. KACT reflects the heparin activity in 